\title{
Development and Application of Casing and Flavor Preparation with Mobile Tanks in Tobacco Industry
}

\author{
Xiaojun Hu, Liang Zhao, Wei Ying* \\ Hangzhou Cigarette Factory, China Tobacco Zhejiang Industrial Co., Ltd.Hangzhou 310002, \\ China \\ Corresponding Author: Wei Ying, Email:yingwei@zjtobacco.com, Tel:18100182598
}

Keywords: tobacco industry; trolley; mobile tank; casing and flavor preparation; high-precision electronic scale

\begin{abstract}
In the traditional casing and flavor preparing system, raw materials are mainly transferred to the tank through pipes, which brings the problems of material loss, flavor mix as well as low accuracy. In order to avoid flavor mix, a mobile tank casing and flavor preparation technique was developed and applied to production. The technique uses an automatic trolley equipped with high precision electronic scale, which shuffles through different raw material tank to get the materials. By doing this, the problem of flavor mix no longer exists and the accuracy of each raw material is above $0.5 \%$, which ensures the product quality.
\end{abstract}

\section{Introduction}

In order to improve the taste quality of cigarette and create varied styles of cigarettes, cigarette factories need to add certain proportional spice and flavor during tobacco processing. Different types of spices or flavors are made of a variety of raw materials in the flavor preparation kitchen. Earlier, the operator needs to weigh the raw materials manually by electronic platform scale before putting them in a blending tank[1]. Whereas, with the expansion of domestic cigarette production, the demand for spice and flavor is increasing, which is pushing the transformation of manual flavor formulation into automate flavor formulation. Up to now, casing and flavor preparation has developed into an all-set automated system made of raw material precalculation, raw material storage and metering, final casing and flavor blending. In the traditional casing and flavor preparing system, raw materials are mainly transferred to the tank through pipes. Therefore, there exists a certain loss during the transfer process[2], which brings the problems of material loss, flavor mix caused by material residue in the pipes, and low accuracy. During the new modification after relocation, Hangzhou Cigarette Factory has built a new mobile casing and flavor preparing system, which has solved the stated problems relatively successfully.

\section{Design ideas}

Casing and flavor preparation system traditionally uses pipeline transportation. The tank and pipes are connected in a "soft" way[3]. The transferred substance can stick to the inside of the pipes, which on one hand, causes material waste and on the other hand, allows material mix since the residue would remain even after the pipe cleaning. Meanwhile, pipe cleaning would require a lot of water, which goes against the concept of green, low-carbon energy-saving economy we now are pursuing. To solve these problems, we came up with the idea of mobilizing the blending tank. According to the requirements of each formula, the blending tank would be able to move to the appropriate raw material storage tank to get the needed material. The mobile tank would be equipped with high-precision scales, ensuring accurate measurement for each raw material.

\section{System structure}

As is shown in Figure 1, the mobile tank casing and flavoring system logically constitutes of three parts, raw 
material precalculation, raw material storage and metering, final blending and caging. While spatially, the system is divided into two floors, with fixed tanks on the upper floor mainly used for distribution and storage of raw materials. Since the measurement at this stage does not require high accuracy, normal cost-saving weighing sensor is used. The mobile tanks are arranged to the lower floor, which is also a blending floor and are equipped with high-grade electronic scales. The tanks are used both as raw material tanks and blending silos, though separately at different time periods. Then after the blending comes caging. There are some exceptions when a very small amount of liquid material is needed or when the raw material is highly viscous. In order to ensure accuracy, these materials are manually added to the blending silo.

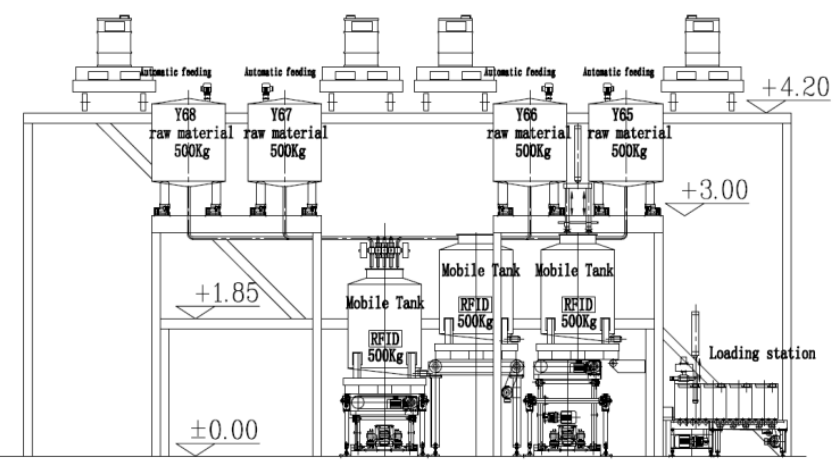

Figure 1. integrated graph of mobile tanks and raw material tanks

As is shown in Figure 2, the mobile tank system runs clockwise on the conveyor belt in a closed-loop fashion. Clean, dry tanks move into the raw material storage section and stops under the corresponding tank to get the required amount of materials after the amount is calculated by the scale according to the formula. The raw material-filled tanks would then be transferredthrough the transverse conveyor to the blending station where two separate blending silos could work simultaneously after the needed solid or thick liquid materials are added. After the blending, the tanks will be transferred to the next position where the final blend will be packed into plastic barrels with the capacity of $25 \mathrm{~kg}$. Next, the empty tanks will be sent to the cleaning station and will at last be dried by hot air after the cleaning.

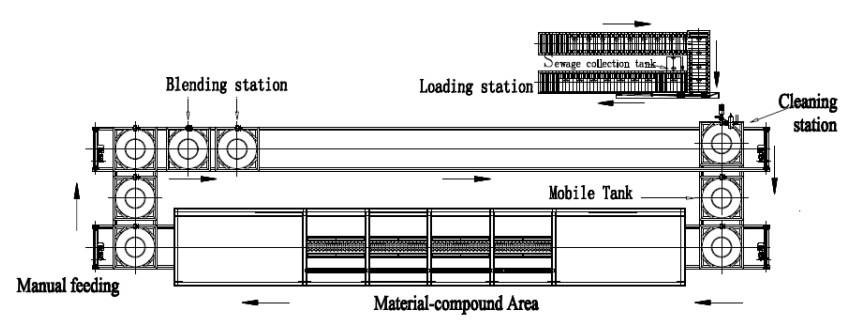

Figure 2. Travel layout of mobile tanks

\section{Key technology}

Being equipped with the high-grade electronic scales for weighing and measuring, this high-precision casing and flavoring preparation system is able to ensure the accuracy and precision on a large scale and is ideal for the operators since it has reached the precision requirements. Furthermore, conveying the materials in mobile tanks prevents raw material mix in a very effective way and avoids the waste of excessive water by obsoleting frequent cleaning required in the blending process before. Thus, the wastewater discharge has been reduced in a dramatic way, lowering the environment pollution.

Mobile tanks are used at the beginning from the raw material measuring and feeding part. The core of this program is to ensure that the tanks can shuffle on the straight tracks on one level. Rail trolleys run relatively more stable than other forms of transportation, and the relative position of the docking process is fixed. The mobile car composes of two parts, that is the mobile trolley body and the high-grade scale placed on it. This trolley is able to maintain maximum blending speed while keeping the liquid transfer steady by using uniform variable speed control technology and ensuring accurate positioning when obtaining the raw materials by laser ranging location technology. The high-precision electronic scale placed on the mobile car is the world's most advanced new K-series made by Mettler-Toledo company. It has a range of $600 \mathrm{~kg}$ and the measuring principle of this scale is differed fundamentally from the other general electronic scales. General electronic scales using strain foil and the weight loaded on it is calculated by using its elastic deformation volume. Since it does not have perfect elasticity and the required elastic coefficient is very high, the precision of measurement is not high. Besides, it has poor repeatability. Whereas, the 
high-precision electronic scale is calculating its load by the principle of electromagnetic induction, the induced current of which can be magnified in an infinite way in theory and there is no need to worry about memory effect. So it has very high measuring precision and a very good repeatability while not affecting the accuracy of measurement. The minimum division values of common range electronic scales (grade III) and high precision electronic scales are shown in table I.

Table I. The minimum division value of common range electronic scales

\begin{tabular}{|l|l|l|l|l|l|}
\hline Common range electronic scales (grade III): \\
\hline Weighing range & $30 \mathrm{~kg}$ & $60 \mathrm{~kg}$ & $\begin{array}{l}150 \\
\mathrm{~kg}\end{array}$ & $\begin{array}{l}300 \\
\mathrm{~kg}\end{array}$ & $\begin{array}{l}600 \\
\mathrm{~kg}\end{array}$ \\
\hline $\begin{array}{l}\text { minimum } \\
\text { division value }\end{array}$ & $10 \mathrm{~g}$ & $20 \mathrm{~g}$ & $50 \mathrm{~g}$ & $\begin{array}{l}100 \\
\mathrm{~g}\end{array}$ & $\begin{array}{l}200 \\
\mathrm{~g}\end{array}$ \\
\hline
\end{tabular}

\section{High-precision electronic scales:}

\begin{tabular}{|l|l|l|l|l|l|}
\hline Weighing range & $30 \mathrm{~kg}$ & $60 \mathrm{~kg}$ & $\begin{array}{l}150 \\
\mathrm{~kg}\end{array}$ & $\begin{array}{l}300 \\
\mathrm{~kg}\end{array}$ & $\begin{array}{l}600 \\
\mathrm{~kg}\end{array}$ \\
\hline $\begin{array}{l}\text { minimum } \\
\text { division value }\end{array}$ & $0.1 \mathrm{~g}$ & $1 \mathrm{~g}$ & $1 \mathrm{~g}$ & $2 \mathrm{~g}$ & $10 \mathrm{~g}$ \\
\hline
\end{tabular}

As we can see from table 1, a high precision electronic scale can measure as little as less than a gram up until hundreds of kilograms while maintaining an accuracy of $0.5 \%$. For example, in the $300 \mathrm{~kg}$-range case, if the required accuracy for the raw materials is $0.5 \%$, its minimum weighing requirement would be 400 grams, which is much more than the minimum division value of the high-precision scale of $2 \mathrm{~g}$. The application of this high-precision electronic scale in casing and flavoring preparation system has greatly improved the accuracy of raw material measurement and has solved the problem of low-capacity devices. It has also transformed the manual measuring modality, realizing the automation of raw material feeding of casings and flavorings.

In this program, two automatic mobile tanks are used for the measurement and obtaining of raw materials and for conveying. They shuffle separately on its own tracks in a straight way to finish their tasks of measuring and blending. During the blending, an operator would send out a command to get the raw materials of the blending, after which the system would automatically load the related information, such as brand name and quantities, etc., from the database to the computer according to the production plan. Then after confirmation, the system will begin to run. The mobile trolley would move quickly to the starting position to get an empty tank while at the same time, the control system is writing the formula information into the electronic tag of that empty tank. After that, the car will automatically move to the first position. After exact positioning, the high-precision electronic scale will be raised to reach the mobile tank, who would then keep rising with the tank to make sure the outlet of the raw material tank valve is inside the mobile tank. At this time, the scale would start measuring before getting the tank filled with the right amount of raw materials. The valve of the raw material tank is also working automatically. It works in three steps, which are big flow at first, small flow once a certain amount from the goal is reached and at last, an inching flow when the required amount is almost reached[4]. In this way, high accuracy of the raw material measuring and is ensured since it can avoid the flow goes out of control due to overly big ball valve opening. Raw material control is optimized by time. In order to get an accurate amount of raw material, the relatively long-time big-flow method is adopted at the beginning and based on the amount needed, the process will end in a pulsating mode over a shorter time.

Before searching for the next picking position, the scale will be lowered down back to the reset position together with the mobile tank while letting the valve outlet of the raw material tank get out of the mobile tank. The electronic scale would reset and calibrate itself automatically during the process. When the process ends, the valve of the last raw material tank is closed and the scale will continue to move to the next required position to get another kind of raw material. After the picking process is finished, the car will then move to the manual feeding station, blending station, packaging station and at last the cleaning station, after which another cycle would begin.

Also, the outlets of the 8 raw material tanks are designed to be placed together, in which way the number of stops are reduced and time is saved.

\section{Application}

After mobile tank casing and flavoring feeding system is put into use, follow up was made to test its reliability and 


\begin{tabular}{|l|l|l|l|l|}
\hline $\begin{array}{l}\text { Blending } \\
\text { name }\end{array}$ & $\begin{array}{l}\text { Raw } \\
\text { material } \\
\text { name }\end{array}$ & $\begin{array}{l}\text { Planned } \\
\text { amount } \\
(\mathrm{kg})\end{array}$ & $\begin{array}{l}\text { Actual } \\
\text { amount } \\
(\mathrm{kg})\end{array}$ & $\begin{array}{l}\text { Deviation } \\
(\mathrm{kg})\end{array}$ \\
\hline $\mathrm{XY}$ & $\mathrm{H} / \mathrm{B} 13500$ & 8.82 & 8.82007 & 0 \\
\hline $\mathrm{XY}$ & JY-18128 & 58.8 & 58.81 & 0.01 \\
\hline $\mathrm{XY}$ & H/B16792 & 44.1 & 44.1 & 0 \\
\hline $\mathrm{XY}$ & HT-0215 & 38.22 & 38.22 & 0 \\
\hline $\mathrm{XY}$ & H/B13518 & 19.11 & 19.11002 & 0 \\
\hline $\mathrm{XY}$ & 960168 & 88.2 & 88.20999 & 0.01 \\
\hline $\mathrm{XY}$ & 8621 & 147 & 147 & 0 \\
\hline $\mathrm{XY}$ & H/B13500 & 8.82 & 8.820007 & 0 \\
\hline $\mathrm{XY}$ & JY-18128 & 58.8 & 58.80997 & 0.01 \\
\hline $\mathrm{XY}$ & 960168 & 88.2 & 88.20001 & 0 \\
\hline $\mathrm{XY}$ & H/B13518 & 19.11 & 19.11 & 0 \\
\hline $\mathrm{XY}$ & H/B16784 & 58.8 & 58.81 & 0.01 \\
\hline
\end{tabular}

accuracy. The accuracy of the blending is shown in table II. For blending XY (name), the deviation of each raw material was less than $0.01 \mathrm{Kg}$, which means the blending accuracy has reached $0.5 \%$.

Testing the density and refractive index of the blending can effectively avoid significant loss which may be caused by the blending applied to tobacco[5]. So, relative density and refractive quality tests were done with the blending samples as well as with controls. The normal range for raw material's relative density and refractive index are \pm 0.0080 and \pm 0.0080 respectively. And for the blending, the two ranges are respectively \pm 0.0040 and \pm 0.0080 . Compared with the control group, the tested samples are all within the normal range. While the samples made with the new technique are having a smaller fluctuation range than the controls in terms of refractive index, as is shown in table III.

Table II. The accuracy table of blending XY

Table III. the relative density and refractive index test of blending $\mathrm{C}$ and flavoring $\mathrm{C}$ in comparison with control

\begin{tabular}{|l|l|l|l|l|l|l|}
\hline Sample & Control 1 & Control 2 & Control 3 & Test sample 1 & Test sample 2 & Test sample 3 \\
\hline $\begin{array}{l}\text { Relative } \\
\text { density }\end{array}$ & 1.1549 & 1.1531 & 1.1538 & 1.1519 & 1.151 & 1.151 \\
\hline $\begin{array}{l}\text { Refractive } \\
\text { index }\end{array}$ & 1.4378 & 1.4373 & 1.4375 & 1.4356 & 1.4356 & 1.4356 \\
\hline
\end{tabular}

\section{6 conclusion}

By adopting the mobile tank technique to the casing and flavoring preparation, the hidden problem of material mix no longer is eliminated. The material loss is reduced dramatically while much more process control is enabled. At present, this system has become an integral part of the casing and flavoring preparation process and a guarantee for normal production. This important advance made in the flavoring technology of the tobacco industry has helped advance the general technical level of the whole industry and has provided an example for the similar products in this area. In conclusion, this technique is highly applicable and is promising to be generalized.

\section{References}

[1] Zhaohui Yuan, Lianbiao Duan. The design of high precision and automatization flavor confecting
system,CHINA

INSTRUMENTATION.2009,12:68-70.

[2] Ronghua $\mathrm{Xu}$, Hai Feng, Jiliang $\mathrm{Hu}$, Yinan $\mathrm{Xu}$, Lin Wang.Research and application of mobile automatic filling and conveying system for tobacco flavor, China New Technologies and Products.2016, 36(4) : 135-139.

[3] Qingwei Liu.Introduction of flavor and casing kitchen system in cigarette factories, China Science and Technology Information. 2011 (10) :193-193.

[4] Guozhong Wu, Yusheng Wu. Discussion on the new flavoring distribution system, Silicon Valley. 2011 (5) :28-28.

[5] Xiaomei Qiu.Application of density and index of refraction for tobacco casings and flavors,Fujian Quality Management, 2011 (9) :62-63. 